\title{
El régimen porfirista y la privatización del subsuelo petrolero
}

Ma. del Carmen Collado $\mathrm{H}$.

Durante el Porfiriato se modificó la legislación minera al otorgar la plena propiedad de los recursos del subsuelo a los superficiarios, rompiendo de esta manera la tradición de propiedad estatal existente desde la etapa colonial. Dicho cambio reflejaba la importancia y el predominio de los terratenientes y más adelante acarrearia una serie de graves enfrentamientos entre los gobiernos surgidos a partir de la Revolución y las empresas petroleras internacionales. La raiz de la pugna se encuentra en otra modificación referente a la propiedad del subsuelo petrolero asentada en la Constitución de 1917. según la cual se restablecia la propiedad estatal nacional de los recursos naturales; es decir que se reivindicaba para el Estado el derecho de cobrar una renta por la propiedad del subsuelo (el aprovechamiento de los recursos subterráneos). Ya desde la etapa maderista se habían establecido los primeros impuestos a la industria de los hidrocarburos, precisamente porque el Estado tomó conciencia de que no estaba participando de las ganancias generadas por este negocio, que para entonces eran importantes. Desde ese momento se inició un forcejeo entre el Estado que intentaba establecer su soberanía impositiva y su propiedad sobre el petróleo (en otras palabras su derecho a cobrar renta) y las compañías petroleras que se negaban a acatarla valiéndose de las exenciones fiscales que se les habian otorgado y de las leyes vigentes durante el régimen de Porfirio Díaz.

El presente trabajo rescata el devenir de la legislación y de la industria petrolera durante el régimen porfirista y analiza desde la perspectiva marxista de la teoria de la renta del suelo las diferentes posiciones frente al problema de la propiedad de los hidrocarburos. A la luz de estos elementos teóricos es factible delimitar las raices de la larga contradicción entre el Estado revolucionario mexicano y las empresas petroleras que culminó con la nacionalización de la industria en 1938.

A continuación se presentan de manera sucinta los elementos conceptuales utilizados en el análisis. De acuerdo con la teoría de la renta del suelo, la existencia de propiedad privada sobre la tierra permite su monopolización y hace posible que los terratenientes cobren una renta por su propiedad, imponiendo así límites a la ganancia media de la clase capitalista.' Este es el origen de la contradicción entre los intereses capitalistas y los terratenientes, pues la renta implica que aquéllos ceden a éstos parte de la plusvalía que extraen a la clase obrera. ${ }^{2}$ De ahí que la libre propiedad esta-

\footnotetext{
' Carlos Marx. Hiscoria critica de la teoria de la plusvalia. México. Fondo de Cultura Económica. 1944. t. II, p. 164-5.

Carlos Marx. El capilal. Buenos Aires. Editorial Cartago, 1973. t. III, p. 646-
} 654. 
tal o propiedad estatal de los recursos naturales, según la cual el Estado no está interesado en percibir renta sino que sólo quiere poner a la libre disposición del interesado los recursos, ${ }^{3}$ sea la condición óptima para el desarrollo del capitalismo. De ahí también la afirmación de Marx en el sentido de que el terrateniente puede convertirse en un "funcionario superfluo" en el mundo industrial. Por lo tanto, de acuerdo con Lenin, el "burgués radical" estaría interesado en la destrucción de la propiedad privada de la tierra puesto que es un obstáculo para el libre desarrollo del capitalismo y por ello hay compatibilidad entre producción capitalista y nacionalización de la tierra, entendida como estatización. ${ }^{4}$ Sin embargo. la burguesía tiende a ver la desaparición de la propiedad privada de los recursos naturales como una amenaza que podría extenderse a la propiedad en general, afectando sus intereses, lo cual explica su oposición y la acusación de socializante a todas aquellas medidas que tienden hacia la estatización de la tierra y el subsuelo. De manera que el capitalismo puede desenvolverse indistintamente tanto en donde existe la propiedad privada de los recursos naturales, como en donde existe la libre propiedad estatal.

Precisamente entre 1876 y 1910 se privatizó el subsuelo petrolero y, al amparo de esa legislación, surgió en México, con capital extranjero, la industria de los hidrocarburos. No obstante, la transición de la propiedad estatal petrolera a propiedad privada enfrentó vaivenes y suscitó discusiones en torno a cuál sería el régimen de propiedad más favorable para el desarrollo de esta industria. El arranque de la industria petrolera se encuentra en los últimos años del Porfiriato, periodo en que se inició firmemente la industrialización con la apertura del país al capital extranjero. La politica de puertas abiertas al capital foráneo coincide con la etapa imperialista durante la cual los países centro buscaron mercados externos para la inversión de capitales. Se creía entonces en México que el capital nacional era insuficiente para poner en marcha el desarrollo industrial y además la mayor parte de los empresarios se mostraban temerosos de invertir en ramas desconocidas para ellos. Asi se desarrollaron las comunicaciones, la banca, el comercio; apareció una industria manufacturera y presenciaron un gran crecimiento la industria minera, la metalúrgica y la eléctrica. Los capitales extranjeros se dirigieron fundamentalmente a la extracción y comercialización de materias primas como era típico del periodo imperialista del capitalismo a principios del siglo.

Las primeras concesiones petroleras con buen éxito otorgadas durante los últimos años de la dictadura fueron dadas a Doheny y Pearson en 1906. Sin embargo, años atrás se habian otorgado otras que no prosperaron; durante el imperio de Maximiliano, entre 1864-1865 se dio trámite a 39 concesiones.

Lá mayor parte de los denunciantes eran mexicanos y las regiones en que se hacían las solicitudes de explotación eran Tabasco y los munici-

"Bernard Mommer y Ramón Rivas, "El petróleo en la transformación burguesa de Venezuela" en Revista de Economia Latinoamericana. Caracas, Banco Central de Venezuela, 1981, núm. 62, p. 209.

"Véase I. Lenin, "El capitalismo en la agricultura" en Teoria de la chestión agraria. México. Ediciones de Cultura Popular, 1976, p. 41-2. 
pios del norte de Veracruz, los del sur de Tampico, la región de Tenancingo en el Estado de México, la región del Istmo y las regiones de Puebla cercanas a la Huasteca. ${ }^{5}$

Dichas concesiones fueron dadas conservando el espiritu de propiedad estatal que provenia de la legislación colonial española, pero ninguna de ellas tuvo buenos resultados, porque por aquellos años no se conocía el uso del petróleo como combustible, faltaban canales de comercialización y habia excedente en el mercado mundial. Para fines de siglo, los hidrocarburos ya tenian una importancia significativa como combustible en el mercado mundial y las naciones industrializadas los buscaban afanosamente. México los necesitaba para la naciente industria y para los ferrocarriles, debido a que el carbón era escaso y poco explotado, de manera que se importaba carbón y pequeñas cantidades de petróleo de los Estados Unidos desde 1902, y se refinaba en la Waters Pierce Company, en Veracruz. ${ }^{6}$

La primera compañía extranjera que invirtió capital para la explotación petrolera fue la London Oil Trust, con un capital de 90000 libras esterlinas. Hizo exploraciones sin éxito alrededor del rio Tuxpam, en el estado de Veracruz. Posteriormente, esta empresa pasó a manos de la Mexican Oil Corporation que invirtió 70000 libras esterlinas más, sin encontrar yacimientos, por lo cual cerró la compañia.'

La primera concesión importante fue dada en 1906 a Sir Weetman Dickinson Pearson, ingeniero inglés contratado por don Porfirio para la construcción de varias obras públicas importantes y que después obtuvo la concesión para la construcción del Ferrocarril de Tehuantepec. ${ }^{8}$ Durante la construcción de la vía férrea fue informado por algunos trabajadores del hallazgo de petróleo, y en 1920 empezó a explorar en busca de yacimientos en la región del Istmo.

El 18 de enero y el 1 de febrero de 1906 se celebraron seis contratos de cincuenta años de duración con la compañía S. Pearson, Son Limited, cuyos intereses absorbió más tarde El Aguila. Dichos contratos hacian posible la exploración y explotación de petróleo en terrenos de propiedad privada en los estados de Veracruz, Chiapas, Tabasco, Campeche y San Luis Potosí. El Estado, según estas concesiones, recibiria una renta del $10 \%$ en el caso de que fueran explotados terrenos de propiedad federal y se estableció que cuando la concesión expirara, el Estado podría disponer de los criaderos de petróleo según su conveniencia. Estos contratos fueron turnados al aparato legislativo en vista de que variaba, en algunas cláusulas, el contenido de la ley petrolera de 1901. Dichas variaciones fueron la exención de impuestos de todo tipo, inclu-

\footnotetext{
5 José Domingo Lavín. Petróleo. México, Fondo de Cultura Económica, 1976, p. 40 .

"Daniel Cosio Villegas. Historia Moderna de México. El Porfiriato. La vida econimica. México, Editorial Hermes. 1965, p. 1126.

${ }^{7}$ Gobierno de México. El petróleo de México. Recopilación de documentos oftciales del conflicto de orden económico de la industria petrolera, con una introducción que restume sus inotivos y' consectuencias, México, Gobierno de México, 1940. reedición de la Secretaría de Patrimonio Nacional. 1963, p. 11.

* José López Portillo y Weber, El petróleo de México, México, Fondo de Cultura Económica, 1981, p. 19-20.
} 
yendo los de exportación, pero exceptuando el impuesto del timbre y el permiso de importación libre de derechos de todo tipo de materiales relacionados con la exploración y explotación durante la vigencia de las concesiones. ${ }^{9}$ En la ley de 1901 se establecía la exención de impuestos pero sólo se daba la exención de impuestos sobre el capital durante 10 años y el permiso para importar maquinaria libre de impuestos por una sola vez. Aunque en El petróleo de México se dice que estos contratos fueron leídos en voz baja en el Congreso para que pasaran por alto las reformas hechas, que permitian hacer exploraciones en terrenos de propiedad privada, cesando así la obligación de pagar al Estado una renta del 10\%, la aseveración carece de fundamento. ${ }^{10}$

Es interesante señalar que en estos contratos figuraba la Cláusula Calvo, es decir que se especificaba claramente que la compañía sería mexicana, a pesar de que sus accionistas fueran extranjeros y que, por lo tanto, no tenian derecho a pedir protección a las embajadas de sus respectivos paises para arreglar asuntos concernientes a las relaciones de la empresa con el gobierno mexicano." En 1908 Pearson, después de haber invertido cinco millones y medio de libras, fundó la Mexican Eagle Company que, más adelante, absorbió algunas pequeñas negociaciones y construyó la refinería de Minatitlán.

Por otro lado, a principios de siglo llegó Edward L. Doheny por invitación de la Central Mexican Railroad a explorar terrenos en la región de la Huasteca, donde había algunas chapopoteras. Doheny habia explorado con éxito algunos campos petroleros en $\mathrm{Ca}$ lifornia. Al poco tiempo de haber llegado fundó, en 1907, la Mexican Petroleum Company con un capital de 10 millones de dólares e inició sus exploraciones en el campamento de El Ebano, San Luis Potosí, sobre el ramal a Tampico del Ferrocarril Central. Doheny recibió el apoyo de Díaz en su empresa y se le dieron los mismos privilegios fiscales que a Pearson, pero Diaz le pidió que en caso de querer vender la empresa, la ofreciera primero al gobierno mexicano, pues no quería que pudiera ser adquirida por la Standard Oil. ${ }^{12}$

Las primeras inversiones de Doheny se canalizaron hacia la compra de terrenos con potencialidad petrolera; así adquirió la Hacienda del Tulillo de 180000 hectáreas y la de Chapacao en el estado de Tamaulipas y otras propiedades en San Luis Potosí, Veracruz, Tabasco, Campeche y Chiapas. ${ }^{13}$ El 14 de junio de 1908 , Doheny obtuvo un contrato de exploración petrolera para aquellos

"Gobierno de México. Diario de los Debates de la Cámara de Diputados del Congreso de los Estados Unidos Mexicanos. XXII Legislatura, México, Gobierno de México. 18 de abril de 1906, p. 231-33.

10 El perróleo de México. Recopilación.... p. XXX.

1 Miguel Alemán, La verdad del petróleo en México, México, Editorial Grijalbo, 1977. p. 22-3. Según este autor, la decisión se debió a la influencia del Congreso de Jurisconsultos de Montevideo de 1888, y al Congreso Jurídico Panamericano de Rio de Janeiro de 1906. La inclusión de la Cláusula Calvo es muy importante porque las reclamaciones de extranjeros ya habian sido causa de invasión durante el siglo pasado en 1836 y 1862 .

12 Lorenzo Meyer, Mévico y' Estados Unidos en el conflicto petrolero (1917-1942), México, El Colegio de México, 1968, p. 37.

${ }_{13}$ Antonio Rodríguez, El rescate del petróleo, México, Ediciones El Caballito. 1975. p. 21, y Lavin. op. cit., p. 48-9. 
terrenos de los cuales era propietario y que estaban ubicados en la Huasteca. $^{14}$

Así narra Doheny sus primeras exploraciones en la Huasteca:

Aquí encontramos un cerro pequeño en forma cónica llamado la Pez, donde burbujeaba un manantial de petróleo, cuya vista nos hizo olvidar el terrible clima, su ardiente y húmeda atmósfera, aquellos montes infestados de moscos, pinolillos y garrapatas, su gran distancia de cualquier centro, que pudiéramos llamar civilizado... Nos convencimos entonces de que nos hallábamos en una región que produciría cantidades ilimitadas de aquello de lo que el mundo tenia mayor necesidad: el aceite combustible. ${ }^{15}$

La producción del primer pozo importante taladrado fue de 1000 barriles diarios que después aumentó a 1700 , y en 1905 se firmó el primer contrato de suministro de combustible con el Ferrocarril Central para entregarle 6000 barriles diarios durante quince años. ${ }^{16}$ Más adelante, Doheny vendió algunas cantidades a la Standard Oil. Doheny creó la Huasteca Petroleum Company con los terrenos de su propiedad, y con los arrendados la Tuxpan Petroleum Company y la Tamiahua Petroleum Company, ${ }^{17}$ ambas subsidiarias de la Mexican Petroleum Company.

La legislación minera colonial reservaba para la Corona la propiedad del subsuelo, en parte por herencia de la legislación medieval, pero sobre todo por la importancia que los españoles dieron a la explotación de metales preciosos que se considerabán base de la riqueza en el periodo mercantilista. De manera que al independizarse, México conservó esa misma tradición, es decir, la propiedad estatal.

Durante la dictadura porfirista se abandonó la tradición jurídica española de propiedad estatal del subsuelo con la finalidad de atraer capitales y agilizar la extracción de hidrocarburos. Sin embargo, ya en el Código Civil de 1870 se asienta el primer antecedente de propiedad privada, pues en el artículo 829 se establece que el propietario de la superficie es también dueño "de lo que está debajo de ella", aunque más adelante se aclara que el dueño de un terreno debe sujetarse a los preceptos de la legislación minera, que entonces todavía mantenía la propiedad del subsuelo en manos del Estado. Esta contradicción entre la legislación minera y el Código Civil se explica según Miguel Alemán porque los autores de este último se inspiraron en el Código Napoleónico. ${ }^{18}$ Pero a nuestro juicio, las tendencias a privatizar el subsuelo eran resultado del creciente poder de la clase terrateniente.

Durante el gobierno de Manuel González (1880-1884) se elaboró el Código de Minería de 1884 que tenía como principal finalidad unificar los criterios en torno a la legislación minera establecidos por la Constitución de 1857 y cuya disparidad se debía a la potestad que dio a los estados para legislar en materia de minas. ${ }^{19}$

It José López Portillo y Weber, El petróleo de Veracruz, México, Comisión Nacional Editorial, 1976, p. 20.

is Enrique A. Quiroz, Tamaulipas, citado por Rodriguez, op. cit., p. 21.

in Cosio Villegas, op. cit., p. 1127.

17 Meyer, op. cit. p. 37.

is Alemán, op. cit., p. 17.

${ }^{19}$ Eduardo Prieto López. Régimen de la propiedad minera y petrolera en México, México, Imprenta Mundial. 1935. p. 20. 
Este código es importantísimo para nuestro estudio ya que con él se rompe la tradición de propiedad estatal para dar paso a la propiedad privada del carbón y el petróleo. En este cuerpo de leyes y en las posteriores, relativas al petróleo, se basarán las compañias petroleras para exigir la no retroactividad del artículo 27 de la Constitución de 1917 que devolvía a la nación la propiedad del petróleo y el carbón.

Es interesante transcribir los párrafos concernientes al petróleo del Código de Minería de 1884.

Artículo. 10. Son de exclusiva propiedad del dueño del suelo, quien por lo mismo sin necesidad de denuncio ni de adjudicación especial, podrá explotar y aprovechar.

I. Los criaderos de diversas variedades de carbón piedra...

IV. Las sales que existàn en la superficie, las aguas puras y saladas, superficiales ó subterráneas: el petróleo y los manantiales gaseosos o de aguas termales y medicinales.

Para el aprovechamiento de todas estas substancias, el dueño del terreeno se sujetará, sin embargo, en sus trabajos a las disposiciones y reglamentos de policía y en la explotación de los carbones minerales y de las otras materias que exijan laborar excavaciones, a las prevenciones de este Código, relativas a la conservación de las minas y la seguridad de los trabajadores... ${ }^{20}$

Como se ve, el Estado renuncia a la regalía al convertir el petróleo y el carbón en propiedad privada. Esta transformación se hizo con el objeto de fomentar la producción de los combustibles necesarios para los ferrocarriles y la naciente industria e ignorando la potencialidad petrolera del país. La ley fue promulgada por el Poder Ejecutivo con base en los poderes especiales que el Congreso le habia conferido y una vez que los estados la habian aceptado. ${ }^{21}$ La facilidad con que entró en vigencia una reforma tan importante es prueba de la poca relevancia que se daba a dichas sustancias.

En 1880 se había llevado a cabo una discusión jurídica en torno a si los minerales debian ser propiedad del superficiario y en tal ocasión Ignacio L. Vallarta, ministro de la Suprema Corte de Justicia, sostuvo la conveniencia de mantener la libre propiedad estatal como una necesidad del "bien público", dejando filtrar en su alegato su pensamiento burgués:

Si la esencia de la propiedad común consiste en el uso o abuso de la cosa a discreción del dueño, en la de las minas su mero uso no está generalmente reputado como medio de esterilizar la explotación de la riqueza pública cosa que a nadie puede ser licita. ${ }^{22}$

Curiosamente, en 1884 no se suscitó ninguna discusión pública por la reforma, pues dejaba a salvo la propiedad estatal de los

2" El petróleo de Mévico. Recopilación.... p. XXVI.

"Lavín. op. cit., p. 41-2 y Cosío Villegas, op. cit., p. 307. El primer autor se confunde y dice que la reforma pasó sin discusión en el Congreso, cuando en realidad, segun hace constar el segundo autor, la reforma fue aprobada en virtud del permiso que le dio el Congreso al Poder Ejecutivo. Lavin también sostiene que la clase terrateniente promovió la reforma para su propio beneficio.

"2 Jesús Silva Herzog. Petróleo mexicano. México. Fondo de Cultura Económica, 1941, p. 60-1. 
metales que eran los que hasta entonces habian sido importantes para la economia mexicana. Seguramente la modificación estuvo inspirada en la legislación norteamericana pues allá existía la propiedad privada del petróleo y el carbón, ${ }^{23}$ y se pensó que el desarrollo por estas industrias se debía a la legislación. Algunos autores sostienen que el cambio en la propiedad se explica por la política liberal, inspiración del régimen porfirista, pero, como hemos visto, el liberalismo no está en contradicción con la libre propiedad estatal. ${ }^{24}$ Al contrario, tal forma de propiedad es muy favorable para el desarrollo del capitalismo. En realidad, el cambio de propiedad estatal a propiedad privada refleja el poder de los terratenientes y su influencia en la política, pues, sin lugar a dudas, ellos fueron el principal sostén del régimen porfirista, la clase dominante.

El 4 de julio de 1892 entró en vigencia la nueva ley minera que tenía la intención explicita de atraer capital extranjero, otorgando las mayores facilidades para la explotación de los combustibles. En el artículo $4^{\circ}$ decia:

El dueño del suelo explotará libremente, sin necesidad de concesión especial en ningún caso, las substancias minerales siguientes:

Los combustibles minerales. Los aceites y aguas minerales... Los trabajos de excavación superficiales o subterráneos que exija la explotación de algunas de esas substancias, quedarán siempre sujetas a los reglamentos que se expidan para la policía y seguridad de las minas. ${ }^{25}$

Sin embargo, en este nuevo código no se dice que el propietario del suelo lo es también del subsuelo hidrocarburado, como sucedía con la ley de 1884 , sino simplemente se da mayor libertad para la exploración y explotación petrolera. En materia propiamente minera se daba un título de explotación a perpetuidad y con carácter irrevocable, mientras se pagara el impuesto federal.

El 24 de diciembre de 1901, cuando tanto Pearson como Doheny habian iniciado exploraciones en busca de petróleo, se promulgó la primera ley específicamente petrolera. José Domingo Lavin en su libro Petróleo sostiene que dicha ley fue creada a instancias de Pearson y Doheny, quienes supieron aprovechar la influencia que tenían sobre el general Diaz. En la ley petrolera de 1901 no se discute a quien pertenece la propiedad del petróleo, simplemente se refiere a la tramitación de concesiones en terrenos federales en los cuales el Estado se reserva la propiedad del petróleo. Esta ley toma precauciones para que las concesiones no puedan ser vendidas a terceras personas, se dan exenciones fiscales por diez años y permisos de importación, pero se mantiene el impuesto del timbre y se impone una regalía del $10 \%$ para el Estado. En la fracción $\mathrm{V}$ del artículo $3^{\circ}$ se establece que la empresa concesionaria tendrá el derecho de expropiar cuando lo requiera, previa indemnización, los terrenos particulares para establecer oficinas o instalar máquinas. A continuación transcribimos los artículos más importantes de dicha ley.

23 Bernard Mommer. Petróleo renta del stuelo e historia, Caracas, Publicaciones de la Escuela de Historia, Facultad de Humanidades y Educación, Universidad Central de Venezuela, 1981 , p. 3.

it Cf. Meyer, op. cit., p. 38 y Silva Herzog, op. cit., p. 61.

25 El petróleo de México. Recopilación..., p. XXVII. 
Artículo $1^{\circ} \mathrm{Se}$ autoriza al Ejecutivo Federal para conceder permisos, a fin de hacer exploraciones en el subsuelo de los terrenos baldios o nacionales y lagos, lagunas y albuferas que sean de jurisdicción federal, con el objeto de descubrir las fuentes o depósitos de petróleo o carburos gaseosos de hidrógeno que en él puedan existir.

Artículo $2^{\circ}$ Los permisos que hayan de otorgarse de conformidad con el artículo anterior, podrán concederse, ya sea a particulares o ya a compañías debidamente organizadas y sólo durarán un ano improrrogable... Durante este tiempo nadie más que la persona o compañía a cuyo favor haya sido otorgado el respectivo permiso, tendrá derecho para hacer exploraciones dentro de la zona a que aquél se refiere para lo cual se señalarán en dicho permiso, y con toda precisión los linderos de ella y su extensión superficial.

Los permisos para exploración causarán un derecho de 5 centavos por hectárea...

Artículo $3^{\circ}$ Las patentes de explotación durarán 10 años; a contar desde la fecha de su publicación en el Diario Oficial. Terminado este plazo cesarán las franquicias y concesiones otorgadas a los explotadores, así como las obligaciones contraídas y que se especifiquen en los articulos correspondientes a esta ley.

Los descubrimientos de petróleo [gozarán de las siguientes franquicias]

I Exportar libres de todo impuesto los productos naturales, refinados o elaborados que procedan de la explotación.

II Importar libre de derechos por una sola vez las máquinas para refinar petróleo y para elaborar toda clase de productos que tengan por base el petróleo crudo, las tuberias...

III El capital invertido en la explotación de petróleo o carburos gaseosos de hidrógeno, será libre por 10 años de todo impuesto federal, excepto el del timbre...

IV Los concesionarios tendrán derecho a comprar los terrenos nacionales necesarios para el establecimiento de sus maquinarias y oficinas al precio de tarifa de los terrenos baldíos que esté vigente en la fecha de la publicación de la patente.

V Para el mismo establecimiento a que se refiere la fracción anterior, y cuando se trate de terrenos que sean de propiedad particular, los mismos concesionarios tendrán el derecho de expropiar [previa indemnización] a dichos particulares...

Artículo $5^{\circ}$ [Sobre el derecho del gobierno a nombrar un inspector]... Este inspector en el caso de que la empresa esté organizada en la forma de sociedad anónima o de sociedad en comandita por acciones, será considerado como miembro del Consejo de Administración y tendrá derecho a examinar todos los datos y apuntes necesarios para emitir a la Secretaria de Fomento, de la cual dependerá, todos los informes que ésta pidiere.

En el caso de que la empresa estuviere organizada en cualquier otra forma de las antes dichas, el inspector tendrá de todos modos derecho a vigilar la contabilidad respectiva, de inspeccionar el manejo de la negociación y las operaciones que en ella se verifiquen, a fin de que éstos produzcan el mejor rendimiento posible y de vigilar también la realización de los frutos...

Las empresas que obtengan patente de exploración estarán obligadas, en cambio de las franquicias que la presente ley les otorga, a pagar anualmente a la Tesoreria General de la Federación siete por ciento y a la del Estado en que se halle la negociación tres por ciento sobre el importe total de los dividendos que decretasen en favor de los accionistas y de los fondos de previsión o de reserva que acordaren separar en cuanto excedan del tanto por ciento que para la formación de dichos fondos señale el Código de Comercio vigente; pero si la negocia- 
ción se encuentra en algunos de los Territorios o en el Distrito Federal se entregará a la Tesorería General de la Federación el total del diez por ciento. Si las mismas empresas no estuvieran organizadas en la forma de sociedad anónima o de sociedades en comandita por acciones las cantidades que deben pagar a la Tesoreria General de la Federación o a la de los estados, en su caso, según previene el párrafo anterior, se calcularán sobre las utilidades líquidas obtenidas. ${ }^{26}$

En el recuento jurídico que hemos hecho del Porfiriato hasta ahora, vemos que a pesar de que en la primera reforma se rompe con la tradición de propiedad estatal en 1884, en el nuevo Código de Minas de 1892 y la ley petrolera de 1901 no se especifica en quién recae la propiedad de los hidrocarburos. Nos inclinamos a considerar que esta ambigüedad a la que dan lugar las dos leyes posteriores a la de 1884 se debió a la indecisión gubernamental en cuanto a qué tipo de propiedad era más conveniente para el desenvolvimiento de la industria petrolera. Ello dio pie a una interesante- discusión juridica llevada a cabo en 1905.

Durante estos años, tanto geólogos mexicanos como norteamericanos llevaron a cabo investigaciones para determinar la potencialidad petrolera de México y todos, salvo Ezequiel Ordóñez, concluyeron que no eran importantes las reservas petroleras del país. ${ }^{27}$ No existian intereses creados y así se explica que el gobierno no se interesara en devolver al Estado una riqueza que podría percibir en forma de renta si el petróleo volvía a pertenecer a la nación, ni diera importancia a los ingresos fiscales que por concepto de petróleo recibiría.

La ley petrolera de 1901 era poco favorable para las compañias petroleras debido fundamentalmente a que la concesión duraba sólo diez años, lapso demasiado breve si se toman en cuenta las altas inversiones que requiere la exploración y explotación y el tiempo que lleva la localización de yacimientos.

En 1905 los abogados Lorenzo Elízaga y Luis Ibarra, representantes legales de Pearson, presentaron un proyecto de ley de petróleo al Ministerio de Fomento. Pearson estaba muy interesado en el establecimiento de la libre propiedad estatal por cuanto resultaba más ventajosa para el capitalista y por tanto no es casual que fueran precisamente sus abogados quienes la plantearan. ${ }^{28} \mathrm{En}$ cambio, el norteamericano Doheny se oponia y deseaba la continuación de la propiedad privada porque él, para entonces, ya poseia importantes cantidades de terrenos con el fin de extraer petróleo. ${ }^{29} \mathrm{La}$ explicación de las posiciones contrapuestas de ambos petroleros se encuentra en la experiencia de sus propios paises de origen. Pearson abogaba por la libre propiedad estatal debido a las consecuencias que trajo a Inglaterra la presencia de la poderosa. clase terrateniente. En cambio, Doheny estaba a favor de la propiedad privada, régimen existente en Estados Unidos, en donde la propiedad privada no fue un obstáculo para el desarrollo del capitalismo debido a la abundancia de recursos naturales.

2" Ihidem, p. 537-9.

${ }^{27}$ Silva Herzog. op. cit., p. 52.

is Lavin, op. cit., p. 50.

29 Carlos Díaz Dufoó. La c'uestión del petróleo, México. Libreria de la Viuda de Ch. Bouret, 1921, p. 154, nota 2. 
El proyecto de los abogados de Pearson fue discutido en la Academia Mexicana de Legislación y Jurisprudencia; en él se proponia la vuelta a la propiedad estatal del petróleo declarando de utilidad pública los trabajos de exploración y explotación petrolera; que se pidieran permisos de exploración en terrenos públicos y privados a la Secretaría de Fomento; derecho de expropiación, previa indemnización de acuerdo a las leyes vigentes, de los terrenos particulares necesarios para la construcción de oficinas y establecimientos industriales y un impuesto a la Tesoreria General de la Federación de 5 centavos por cada 150 litros de petróleo o por cada 1500 litros de carburos gaseosos. El proyecto establecía que se respetarían los contratos anteriores con terratenientes a quienes se debería pagar una regalia igual a la que se proponía para el Estado. ${ }^{30}$ No obstante, la mayor parte de los votos fueron contra la reforma, por lo cual ésta fue archivada y la legislación permaneció tal como se había mantenido entonces. Es interesante analizar las ideas más importantes vertidas. en ese momento porque los argumentos que las compañias esgrimieron más tarde para oponerse a la nacionalización del petróleo fueron en esencia los mismos que se expusieron en 1905 .

Los licenciados Elizaga e Ibarra se basaban primordialmente en la utilidad pública para fundamentar la necesidad de la reforma propuesta. Afirmaban:

No teniendo en el país otro combustible que los árboles, en inconcuso que la industria petrolera deba tener la primacía entre todas las industrias declaradas de utilidad pública, porque es la base de todas ellas; y si la ley protege al que aprovecha el carbón blanco o sean las caidas de agua por más que las aguas sean de particulares y corran por la superficie ¿por qué coartar las exploraciones y explotaciones de petróleo, cuando nadie posee ni es dueño de los depósitos de esas substancias? ${ }^{31}$

La segunda parte de su argumentación consistia en la negación de que el dueño del suelo lo es también de las sustancias del subsuelo. mientras no conozca su existencia ni haya iniciado trabajos para explotarlas. Para justificar la necesidad de hacer la división entre propiedad superficial y propiedad del subsuelo, Elizaga e Ibarra hicieron una docta exposición de aquellos juristas clásicos, entre mexicanos y extranjeros, que se habían pronunciado por ella. ${ }^{32}$

Los abogados Emilio Pardo, Francisco Beíztegui, Fernando Vega, Miguel Mejia, Isidro Rojas y Roberto A. Esteva y Ruiz vertieron opiniones apoyando la reforma propuesta por Elizaga e Ibarra y además añadieron que había que:

...reincorporar al movimiento industrial y económico de la República aquellas riquezas naturales de la tierra que en mala hora una disposición legal arrebató del dominio público, al hombre en general o sea a la humanidad para concentrarla inculta, improductiva e inaprovecha-

30 Lorenzo Elizaga, et al., Proyecto de ley del petróleo y exposición de motivos de la misma que presentan al Ministerio de Fomento los señores licenciados Lorenzo Elizaga y' Luis Ibarra y' el ingeniero Mantel Fernández Guerra, México, Talleres Tipográficos de El Tiempo, 1905, p. 20-1.

31 Ibidem. p. 4-5.

32 Ibidem. p. 9. 
ble en manos de los señores territoriales que las guardan y esconden con la misma avidez que el avaro oculta sus tesoros. ${ }^{3.3}$

Se argumentaba para pedir el establecimiento de la libre propiedad estatal que:

...esta clase de propiedad sujeta siempre a las evoluciones económicas y a los intereses de la industria y el comercio. nunca ha conservado. forma definitiva. siempre ha sentido las alternativas del interés social [...] nos unimos [...] para desestancar, para movilizar el carbón y el petróleo que la indolencia o el capricho o la impotencia de los actuales superficiarios mantiene ocultos en las entrañas de la tierra o substraídos a la acción de nuestro progreso industrial. ${ }^{34}$

Se puede apreciar en las ideas hasta ahora analizadas, que para estos abogados los intereses industriales y comerciales eran fundamentales en la sociedad, es decir, que representaban al "burgués radical" que podía luchar contra los terratenientes si sus intereses se veían amenazados por los de éstos. En realidad, son los defensores de los intereses del capital.

Para emprender con ventaja y de una manera regular y durable las exploraciones y explotaciones de petróleo, se requiere una gran superficie, pues la investigación preliminar debe comenzar por localizar la zona productora. abriendo numerosos pozos... dada la peculiarísima naturaleza de los depósitos de petróleo para encontrar un pozo que dé algunos resultados, tienen que hacerse exploraciones de una gran extensión. Ahora bien, esta empresa, la naturaleza de esta industria extractiva es aleatoria por excelencia, y si alguna persona se atreve a emprenderla es porque sabe que si en determinada extensión no han dado resultado sus exploraciones, teniendo éxito en cualquier otro lugar puede resarcirse de los gastos antes hechos y obtener alguna ganancia. Este problema económico es perfectamente claro, y entonces, si concediéramos el derecho de exploración y explotación del petróleo únicamente al dueño del suelo... nunca se atreveria a invertir las grandes sumas necesarias para la exploración sabiendo que no obstante las manifestaciones a que antes se ha hecho referencia, pudiera no existir el petróleo en terreno de su propiedad sino en los de la propiedad del vecino y que al llegar a sus linderos la ley impidiera seguir adelante, con ese pretendido respeto al mal entendido derecho de propiedad respecto al subsuelo. ${ }^{35}$

Estos mismos argumentos fueron apoyados y ampliados por Emilio Pardo y Francisco Beíztegui para proceder a la reforma que declaraba el cambio de propiedad por causa de utilidad pública. $^{36}$

Las opiniones en contra del proyecto de ley se basaban en el respeto a la propiedad privada, y defendian los intereses de los

3 Salvador Mendoza, La controversia del petróleo, México, Imprenta Politécnica, 1921, p. 395. Opinión del licenciado Miguel Mejia.

${ }^{34}$ Thidem. p. 359 y 366 . Opinión del licenciado Fernando Vega.

3 Elizaga, op. cit., p. 11-14.

36 Emilio Pardo y Francisco Beíztegui, Opiniones de los señores licenciados Emilio Pardo (jr.) y Francisco Beiztegui acerca del provecto de Ley de Petróleo y sus fiundamentos que presentaron al Ministerio de Fomento los licenciados Lorenzo Elizaga y Luis Ibarra y' el ingeniero Manuel Fernändez Guerra, México, Imprenta de R. Amilieu Lacaud. 1905, p. 6-7. 13-14 y 20. 
terratenientes; aparecen ya entonces las acusaciones de "socialistas". que tantas veces se repetirán después, contra los defensores de la propiedad estatal. Asimismo, se niegan a aceptar la propiedad estatal del petróleo porque ya existen "derechos adquiridos" y por lo tanto una ley de esa indole seria retroactiva y por ende anticonstitucional.

A este respecto el licenciado Méndez se pronunció por que "...la causa de necesidad pública no puede ser invocada para fomentar la producción de esas substancias quebrantando la propiedad privada". ${ }^{37}$ El licenciado Rodolfo Reyes dijo que “...La teoria del libre denuncio ataca por su base el principio individualista y establece real y positivamente el socialismo de Estado pues a nombre de los intereses de éste se posterga y desconoce los del individuo." 38 Más adelante, citando la intervención del licenciado Jacinto Pallares añade:

...Ahora se comprenderá cómo deben desaparecer todas las restricciones arbitrarias que en nombre de la conveniencia y del interés público se han inventado por legisladores y autores para sacrificar al individuo en nombre de la colectividad. ${ }^{39}$

Y nuevamente apoyado en lo afirmado por el licenciado Requena dice:

...La posesión de una cosa ampara la de que todas sus partículas y componentes sean conocidos, inciertos o desconocidos y en consecuencia esa posesión existe sobre todas las materias inorgánicas que tiene el suelo. ${ }^{40}$

Pesaron más las opiniones de los enemigos de la reforma y la comisión ministerial votó en contra, defendiendo la nó retroactividad de las leyes. ${ }^{41}$ Se puede decir entonces que, en aquel momento, triunfaron los intereses de los terratenientes y de Doheny, quien en palabras de Lenin se habia convertido en un burgués territorializado. ${ }^{2}$. Indudablemente existe una ambigüedad en la defensa de la libre propiedad estatal de los recursos naturales por parte de la burguesía, pues si bien desde el punto de vista ideal es conveniente para sus intereses por desaparecer la renta absoluta, al mismo tiempo necesita la existencia de la propiedad privada de los medios de producción. Tal contradicción es propia del capitalismo y, como vimos, en esta ocasión perdió el "burgués radical" y triunfaron los intereses de los terratenientes y los de aquellos burgueses "territorializados" que sentian amenazados sus intereses cuando se trataba de limitar la propiedad privada. Situación

\footnotetext{
37 Mendoza, op. cit. Opinión del licenciado Luis Méndez, presidente de la Academia Mexicana de Legislación y Jurisprudencia, p. 303.

$3 *$ Ihidem. p. 329. Resumen de la discusión formulada por el licenciado Rodolfo Reyes.

Ihidem, p. 348 .

ti) Ibick'm. p. 265. Opinión del licenciado José Luis Requena.

+1 Ihidem, p. 350.

t2 Lenin. "Los fundamentos teóricos de la nacionalización", en op. cit.. p. 239. Aqui Lenin explica que en muchos casos la burguesia queda ligada a la posesión de la tierra en proporciones vastas, a lo cual llama "territorialización" de la burguesia, y entonces se opone a la libre propiedad estatal.
} 
explicable sobre todo en el caso de México; se trataba de un país que no había dejado de ser agrícola y en donde la tierra representaba una de las mayores fuentes de riqueza.

El 25 de noviembre de 1909 entró en vigor la nueva ley minera que declaró definitivamente la propiedad privada del petróleo, dando pie a la legalización de los contratos con los superficiarios; fue base para la creación de concesiones confirmatorias. ${ }^{43}$ De igual manera, las compañias se apoyaron en esta ley que ya no deja ninguna duda respecto a la propiedad privada del superficiario para defender sus intereses. En su artículo segundo declaraba:

Son de propiedad exclusiva del dueño del suelo:

I Los criaderos o depósitos de combustibles minerales bajo todas sus formas y variedades.

II Los criaderos o depósitos de materias bituminosas. ${ }^{44}$

El petróleo mexicano pronto atrajo la atención de otros inversionistas extranjeros y consecuentemente Doheny y Pearson perdieron el monopolio del que disfrutaban. Se establecieron numerosas empresas norteamericanas: Waters Pierce, Standard Oil, Texas Mexican, Gulf Refining, Texas Mexican Fuel, Penn Mexican Fuel, Sinclair Southern Oil \& Transport, Pánuco-Boston; se firmaron hasta doscientos noventa contratos con compañias norteamericanas. No obstante, la mayor inversión provenía del grupo Pearson con la Mexican Eagle Company, de capital anglocanadiense; su inversión era de 6400000 libras esterlinas, de las cuales 680000 estaban en manos francesas. Después seguia el grupo Doheny con la Mexican Petroleum Company y sus subsidiarias, con una inversión de 10 millones de dólares, y por último la Standard Oil y Waters Pierce reunidas en la Mexican Fuel Company con 10 millones de dólares. ${ }^{45}$

Aunque para 1911 la inversión extranjera en el petróleo sólo representaba el $3.1 \%$ del total, rápidamente fue adquiriendo importancia.

INVERSIÓN EXTRANJERA EN EL PETRÓLEO*

Paises

Gran Bretaña

Estados Unidos

Francia
Pesos

57200000

40000000

6800000
Porcentajes

$55 \%$

$38.5 \%$

$6.5 \%$

* Datos tomados de Daniel Cosio Villegas, Historia moderna de México. El Porfiriaro. La vida económica. México, Editorial Hermes, 1974, p. 1129. Aunque entre los inversionistas de El Aguila se contaba a Enrique Creel y Porfirio Diaz hijo, es indudable que el capital mexicano tuvo muy poca importancia.

4.3 El petróleo de Mévico. Recopilación..., p. 14.

th Ihidem. p. 540.

t5 Cosio Villegas, op. cil., p. 1129. 
En 1905 se realizó el primer gran hallazgo petrolero, excavando en las cercanías de la laguna de Tamiahua, Veracruz; se perforó el famoso pozo Dos Bocas a 566 metros de profundidad; la fuerza del petróleo fue tal que destruyó la torre y se incendió el pozo, que ardió sin interrupción durante 53 días. Se calcula que de ahí salieron unos 11400000 barriles. ${ }^{46}$ En la región de la Huasteca se perforó el Juan Casiano núm. 7 que produjo, durante su vida, 85 millones de barriles y en diciembre de 1910 se encontró el Potrero del Llano núm. 4 que tuvo una producción de 117 millones de barriles. El boom petrolero mexicano se había iniciado y con él la afluencia de inversionistas.

Si bien los costos de perforación eran tres veces más altos que en Estados Unidos, la gran riqueza de los pozos los justificaba con creces; la mayoria de ellos brotaban por su propia presión, sin necesidad de bombeo. El embarque y transporte era muy económico y llegaba a precios competitivos a la costa este de los Estados Unidos. ${ }^{47}$

La importancia de la industria petrolera para la economía nacional no fue muy grande durante el Porfiriato, cosa explicable por lo nuevo de la actividad, pero de haber constituido el $0.01 \%$ del producto interno bruto en 1904 , llegó al $0.16 \%$ en $1908 .^{48}$ En materia fiscal los ingresos petroleros no tuvieron ninguna importancia debido a la política de exenciones y facilidades para la industria petrolera puesta en marcha por don Porfirio.

En este mismo periodo se establecieron tres refinerias: la Waters Pierce fundó en 1886 una pequeña en Veracruz, en 1898 otra mayor en Tampico y la refinería El Aguila de la compañía del mismo nombre en Puerto México en $1910^{49}$

\section{PRODUCCIÓN DEL PETRÓLEO*}

Años

1901

1902

1903

1904

1905

1906

1907

1908

1909
Barriles

10345

40200

75375

125625

251250

502505

1005000

3932000

2713500

* Datos tomados de Lorenzo Meyer, México y Estados Unidos en el conflicto petroloro (1917-1942). México. El Colegio de México, 1968. p. 19.

th Rodriguez, op. cit., p. 22-3.

t7 James Becket. "The mexican petroleum industry under foreign ownership (1901-1938): an estimate of retained value". de la tesis The economic consequences of the nationalization of foreign owned enterprises in under-developed countries. Case Sudics in Political Econom!; s.p.i.. 1969, p. 3.

ts' Meyer. op. cit., p. 29.

14 Cosio Villegas, op. cit., p. 13. 
En muchos casos los dueños de los terrenos petroleros preferían por ignorancia una suma adelantada como regalía; otros optaban por una renta anual de 5,10 y hasta 25 pesos por hectárea y una participación en la producción que oscilaba entre el 5 y el $10 \%$ y solo excepcionalmente $25 \%$. Aunque no contamos con datos precisos para este periodo es de suponer que la mayoria de los contratos fijaba una regalía de $5 \%$ o sea $1 / 20$, suma muy inferior al $1 / 8$ predominante en Estados Unidos, ${ }^{50}$ pues hasta 1914 era lo común en la región de Tuxpan y ya de 1916 en adelante dominó el $10 \% .{ }^{51}$ Tampoco poseemos cifras para la cantidad de terrenos adquiridos y arrendados por las compañias; lo más probable es que predominaran los arrendamientos, pues para 1921 aproximadamente el $75 \%$ de las tierras en explotación correspondía a arrendamientos. Aún así, el $25 \%$ de tierras propiedad de las compañias no es nada despreciable y explica la territorialización de algunas compañias capitalistas. ${ }^{52}$

Es importante hacer un recuento de las fricciones entre el gobierno norteamericano y el de Díaz porque en ellas estuvieron presentes los intereses petroleros, si bien la caida de la dictadura se explica por causas internas. Como hemos dicho, una de las preocupaciones de la administración porfiriana fue evitar el predominio de la inversión norteamericana en México, lo cual evidentemente provocó recelos en los Estados Unidos. En conformidad con esta política, Díaz canceló una concesión a la Standard Oil, quien tuvo que unirse a la Waters Pierce para seguir en México. Asimismo, la creación de un impuesto de importación de petróleo afectó seriamente a la Waters Pierce ya que lo importaba para después refinarlo y venderlo en el país. Se desencadenó una guerra de precios entre Pearson y Pierce y finalmente ganó Pearson gracias a que la Standard Oil abandonó a su aliada y pudo penetrar el mercado nacional. ${ }^{53}$ También hubo roces debido a los intereses de la Guggenheim que no fueron respaldados por Limantour, el ministro de Hacienda. La adquisición del $50 \%$ de las acciones ferrocarrileras mexicanas por el gobierno, fue nueva causa de desavenencia entre los intereses privados norteamericanos y el régimen mexicano. El disgusto de Pierce por el respaldo dado a Pearson lo llevó a ponerse en contacto con los rebeldes maderistas $\mathrm{y}$ a ofrecer un préstamo que oscilaba entre medio millón y un millón de dólares, según los autores que hablan de este caso. ${ }^{54}$ Aunque no se ha podido comprobar si se hizo efectivo el préstamo, fue conocido por el Departamento de Estado norteamericano, quien llamó la atención a la Standard Oil por su injerencia en el asunto.

En las relaciones entre el gobierno de Taft y el de Diaz, varios incidentes crearon un ambiente de frialdad: la disputa por El Chamizal, territorio que había quedado del lado norteamericano por modificaciones del cauce del río Bravo y cuya devolución México reclamaba, la negación de Díaz a renovar el arrendamiento de $\mathrm{Ba}$ -

51) Mommer, Petróleo, renta..., op. cit., p. 8.

st Diario Oficial. México. 21 de enero de 1918, citado en Díaz Dufoó, op. cit., p. 99.

\footnotetext{
$\therefore$ Ibidem, p. 96.

53 Meyer, op. cit., p. 42.

it Ihidem, p. 42-3.
} 
hia Magdalena para una base naval norteamericana, el apoyo del dictador a Zelaya, político nicaragüense derrotado con la anuencia de Estados Unidos y el acercamiento de México a Japón. ${ }^{55}$

A pesar de las fricciones, Estados Unidos todavía tenía confianza en el gobierno de don Porfirio cuando estalló la revolución maderista en noviembre de 1910. Pero hacia marzo, empezó a dudar de la capacidad del gobierno mexicano para detener la lucha armada. Si bien el gobierno norteamericano no ayudó directamente a los revolucionarios mexicanos que estaban exiliados en su país; apoyándose en la neútralidad asumida en el conflicto, los dejó actuar libremente; en algunos casos, las autoridades menores norteamericanas les dieron todo su apoyo y no impidieron que recibieran ayuda de sus compatriotas en Estados Unidos. ${ }^{56}$

Llegaba a su fin una dictadura de más de treinta y cinco años durante la cual México conoció un largo periodo de paz, fincada en la represión y el control del poder a todos niveles, que le permitió un importante crecimiento económico manifestado en la minería, la banca, la industria manufacturera, la metalúrgica, el comercio, y en el que tuvieron un papel.destacado las inversiones extranjeras. El régimen de privilegio que caracterizó al Porfiriato provocó la marginación y empobrecimiento de los más vastos sectores de la sociedad mexicana: los campesinos y la naciente clase obrera, y basó su fuerza en el respaldo a la oligarquía terrateniente, la naciente burguesía y los capitalistas extranjeros. No obstante, el tránsito hacia el capitalismo que México iniciaba se encontró con el obstáculo del latifundismo y así las propias contradicciones engendradas por el porfirismo, lo llevarian al colapso. Inmersa en estas circunstancias se inició la explotación petrolera en México y se modificó la legislación minera hasta establecer de forma inequívoca la propiedad privada del subsuelo petrolero. Este importante cambio en el régimen de propiedad revela la significación de los terratenientes del periodo y su pertenencia a la clase dominante, al tiempo que rompe con la tradicion heredada de la Colonia. Claro está que la novedad de la explotación petrolera en México y la poca importancia que se le asignó a la riqueza. de los hidrocarburos, de alguna manera explican la facilidad de la transición a la propiedad privada con la consecuente renuncia del Estado a participar de la renta generada por el recurso natural. Sin embargo, no compartimos la afirmación de que el cambio de propiedad estatal a propiedad privada es producto del liberalismo económico característico del régimen como lo afirman algunos autores, pues según ya se ha demostrado, tanto la propiedad privada de los recursos naturales como la libre propiedad estatal son perfectamente compatibles con el liberalismo económico. Más aún, la forma de propiedad ideal para el desarrollo del capitalismo es la libre propiedad estatal de los recursos naturales puesto que con ella desaparece definitivamente en la sociedad la importancia de la clase terrateniente y por ende de la renta; aunque cabe recordar que el estado capitalista cuenta con otros instrumentos para dis-

\footnotetext{
s5 Jorge Vera Estañol, La Revolución mexicana. Origenes y' resultados, México. Editorial Porrua, 1957, p. $105-13$.

56 Daniel Cosio Villegas, et al., Historia General de México, El Colegio de México. 1976. Vol. 4, p. 8-10.
} 
minuir la importancia de la renta en la economia; por ejemplo, la aplicación de impuestos.

Si la Revolución mexicana de 1910 fue desde el punto de vista juridico la sepultura de los terratenientes, también lo fue de los superficiarios y de las compañias petroleras que se negarían a reconocer la propiedad estatal nacional de los hidrocarburos, reivindicada para la nación por el artículo 27 de la Constitución de 1917, mas ambos procesos serian largos y tortuosos y culminarian los dos durante el régimen de Cárdenas. 